\title{
Method of calculating the preferred approach in the evaluation of intellectual property
}

\author{
Sofya Dyakonova ${ }^{1, *}$, Lyudmila Shevchenko ${ }^{1}$, Elena Sharapova ${ }^{1}$ and Oleg Shalnev ${ }^{1}$ \\ ${ }^{1}$ Voronezh State Technical University, Moscow Avenue, 14, Voronezh, 394026, Russia
}

\begin{abstract}
The paper presents a method for calculating the preferred approach when evaluating intellectual property, taking into account local confidence factors, which makes it possible to obtain the final value of intellectual property with high probability and accuracy, using three wellknown approaches. This method has a high practical significance, since all evaluators have to constantly face the choice of the preferred approach. Local confidence factors have been developed with the respect to the type of intellectual property, the type of production, the stage of the life cycle, the purpose of using the object, the value of the indicator deviation from the average value. The influencing factor determines the local confidence factor for each method of evaluation separately through the established functional dependence. The method used neural network modeling, which allows quickly solving a whole range of problems in a single method.Using the proposed method, it is possible to automatically calculate the weighting coefficients of the income, cost, and comparative method, ensuring the necessary accuracy of the final value.
\end{abstract}

\section{Introduction}

Nowadays, the development of the economy of countries of the world and individual industries is determined not only by the scale of production but also by its innovative component. Almost all enterprises own technologies, inventions, and also have registered trademarks. And this means that the majority of intellectual objects participating in the activities of an enterprise require an assessment of their value.

However, determining the value of intellectual property and intangible assets is a complex, time consuming and creative process. In practice, evaluators have to face uncertainty, risks, lack of information, imperfect calculation methods, which distorts the real value of intangible assets. The total value of the object depends on the accepted base of assessment, the amount of information about the data for evaluation, and the approaches and methods used for evaluation.

According to international evaluation standards, the result of the determination of the value of the object is the value of a reasonable generalization of the values obtained using different methods in the three generally accepted approaches. However, the value of cost is correspondingly different in each approach.Therefore, it is necessary to weigh the probability of the reliability of each approach and justify the use of each of the evaluation

*Corresponding author: sof1355@yandex.ru 
methods, which will result in one independent total cost of the evaluation out of three independent values [1].

The most accurate evaluation is shown by the main approach. The second place indicates, as a rule, an approach that has a number of shortcomings, for example, a lack of information about the object of evaluation, which may already lead to inaccuracy in obtaining data. However, it can complement and confirm the results of the main approach. The third can be called an inefficient approach, when the result is the least accurate value, but there is no opportunity and data for a more effective approach [2].

It is believed that with a developed information field, a sufficient amount of necessary data, and the correct choice of evaluation methods, the calculation results for the three approaches should be close in value. However, during the evaluation, it is rather difficult to obtain objectively consistent data. The very specificity of intellectual property objects (IPO) is such that the use of all approaches used in evaluation practice is impossible. Earlier studies have indicated the problematic use of income and cost approaches in the evaluation of intellectual property [3,4]. But it is especially difficult and not recommended to determine the cost of innovative objects by a comparative approach due to the lack of many factors for comparison.

Exclusively for objects of intellectual property in order to increase the objectivity of the calculations, it is possible to use two or more methods of one approach, for example, only income (or cost), since often other approaches cannot be used for reasons of lack of data, lack of information, incompatibility of some objects with traditional methods and etc.

\section{Materials and Methods}

Therefore, the coordination of the final evaluation data can be called the main problem leading to the distortion of the effective indicator. It is necessary to give specific weights in accordance with the most reliable data to the results obtained with the help of all three approaches and justify the assumptions made.

The total cost of the evaluation is calculated using the expression:

$$
\mathrm{C}_{\text {total }}=\mathrm{C}_{\text {exp }} \times \mathrm{a}_{\text {exp }}+\mathrm{C}_{\text {inc }} \times \mathrm{a}_{\text {inc }}+\mathrm{C}_{\text {market }} \times \mathrm{a}_{\text {market }},
$$

where $\mathrm{C}_{\text {total }}$ - total evaluation cost;

$\mathrm{C}_{\text {exp }}, \mathrm{C}_{\text {inc }}, \mathrm{C}_{\text {market }}$-costs obtained usingcost (expense), income, and comparative (market) approaches, respectively,

$a_{\text {exp }}, a_{\text {inc }}, a_{\text {market }}$ - relevant weights of evaluations, $a_{\text {exp }}+a_{\text {inc }}+a_{\text {market }}=1$.

Weights $a_{\text {exp }}, a_{\text {inc }}, a_{\text {market }}$ are determined on the basis of confidence in the results of applying three different approaches to the assessment, which depends on the completeness and reliability of the source data, as well as the various assumptions and presumption used $[5,6]$.

However, in the proposed method (as in other well-known ones), the risk of obtaining an inaccurate result is still significant.

We have developed our own method of choosing the preferred approach, based on the dependence of the life cycle on the evaluation objectives, the type of IPO, the type of cost and the factors affecting the cost.

The main idea of the method is to create a model that allows determination of the level of confidence (the concept of "level of confidence" can be replaced by the concept of "level of significance") for various methods of evaluating intellectual property (IP) depending on the values of individual factors of the object being evaluated.

Each of the influencing factors determines the local confidence factor for each method of evaluation separately through the established functional dependence. The aggregate of 
local confidencefactors of one of the evaluation methods forms the resulting confidence factorof this evaluation method, which is its specific weight in the final calculation of the IP value.

The values of the confidence factorsare determined depending on the local confidence factors, and those, in turn, depend on the following factors:

1. Type of IP (according to the classification);

2. Type of production when using IP (serial production);

3. Stage of the life cycle of IP;

4. The purpose of the IPevaluation;

5. Deviations of the indicators obtained as a result of the IP evaluation in various ways.

Thus, to determine the final value of the confidence factor, it is necessary to calculate 5 local confidence factors depending on the factors listed above.

One of the key elements in the development of the considered methodology for evaluating the IP was the establishment of a functional relationship between the local confidence factor and the indicator characterizing the influencing factor. The values of expert estimates were used as the initial data to determine the functional dependence. Prior to the identification of empirical dependencies, the initial data were approximated using neural network modeling $[7,8]$.

Neural networks allow us to effectively model non-linear systems with hidden dependencies. With their use, you can almost automatically take into account the various non-linear relationships between the indicators - the signs characterizing such data.

The advantages of neural network modeling include the ability to solve a whole complex of problems in a single methodology (paradigm). At the same time, the disadvantages of neural networks should include difficulties with the interpretation of inference rules and the presentation of these rules in an explicit form.

The neural network approach allows solving complex, poorly formalized tasks in a shorter time, including the construction of expert systems. Methods of a detailed statistical analysis provide a detailed analysis of the data structure and allow selecting semi-analytical models of processes. Such semi-analytical models provide an opportunity to answer a number of important practical questions. In the problem we are solving, such a question is the choice of the main method during the IPevaluation.

The structural model of an artificial neuron is shown in Figure 1.

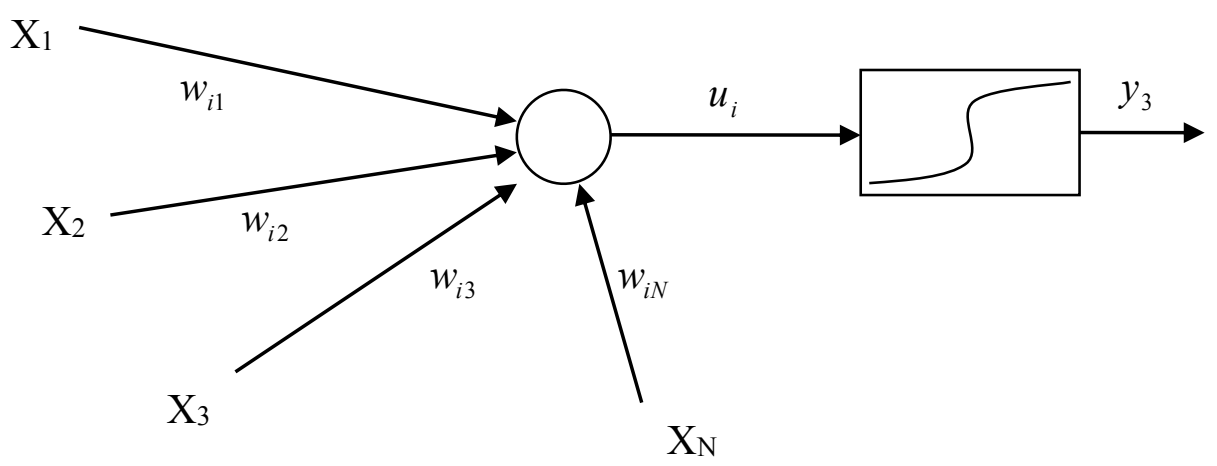

Fig. 1. Structural model of an artificial neuron.

All the features of neural networks are in their structure. By interconnecting neurons, you can get a network capable of displaying a complex data structure. In fact, to solve most of the problems, it is enough to use three-layer neural networks. The first layer of neurons in the network is called the input, the last - the output. Some known signals are input, and 
some expected output is expected at the output. In this case, the system modifies its parameters as new examples are presented to it in order to reproduce the output signal most accurately.

\section{Results}

Calculation of the local confidence factor on the basis of the type of production.

Table 1.The data obtained as a result of the approximation of expert evaluations using a neural network.

\begin{tabular}{|c|c|c|}
\hline № & $\begin{array}{c}\text { Factorof "Fixing operations } \\
\text { (serialization)" }\end{array}$ & $\begin{array}{c}\text { Significance (confidence) of the } \\
\text { income evaluation method }\end{array}$ \\
\hline 1 & 0 & 61.56983 \\
\hline 2 & 4.666667 & 59.84079 \\
\hline 3 & 9.333333 & 57.65555 \\
\hline 4 & 14 & 54.89951 \\
\hline 5 & 18.66667 & 51.45074 \\
\hline 6 & 23.33333 & 47.19535 \\
\hline 7 & 28 & 42.05184 \\
\hline 8 & 32.66667 & 36.00276 \\
\hline 9 & 37.33333 & 29.12603 \\
\hline 10 & 42 & 21.61296 \\
\hline
\end{tabular}

$$
\begin{gathered}
A * 10383702+B * 279888+C * 7971=248942 \\
A * 279888+B * 7971+C * 252=8904 \\
A * 7971+B * 252+C * 11=483 .
\end{gathered}
$$

After solving the system of equations, the following parameter values were obtained:

$$
\mathrm{A}=-0.022 ; \mathrm{B}=-0.000005 ; \mathrm{C}=66.01 \text {. }
$$

Substituting the obtained coefficients A, B and C, we have:

$$
y=-0,022 x^{2}-0,000005 x+60
$$

The value equal to the product of the factor of fixing operations and 0.000005 is not significant when considering the issue of confidence in the income evaluation method, therefore the final formula for calculating the local confidence factor of the income method with respect to the type of production will be as follows:

$$
\begin{aligned}
\mathrm{TP}_{\text {inc }} & =60-0,022 * \mathrm{~K}_{\mathrm{o}}^{2} \\
\mathrm{TP}_{\text {exp }} & =6+0,037 * \mathrm{~K}_{\mathrm{o}}^{2} \\
\mathrm{TP}_{\text {market }} & =34-0,015 * \mathrm{~K}_{\mathrm{o}}{ }^{2}
\end{aligned}
$$

$\mathrm{K}_{\mathrm{0}}$-“Fixing operations (serialization)"factor 


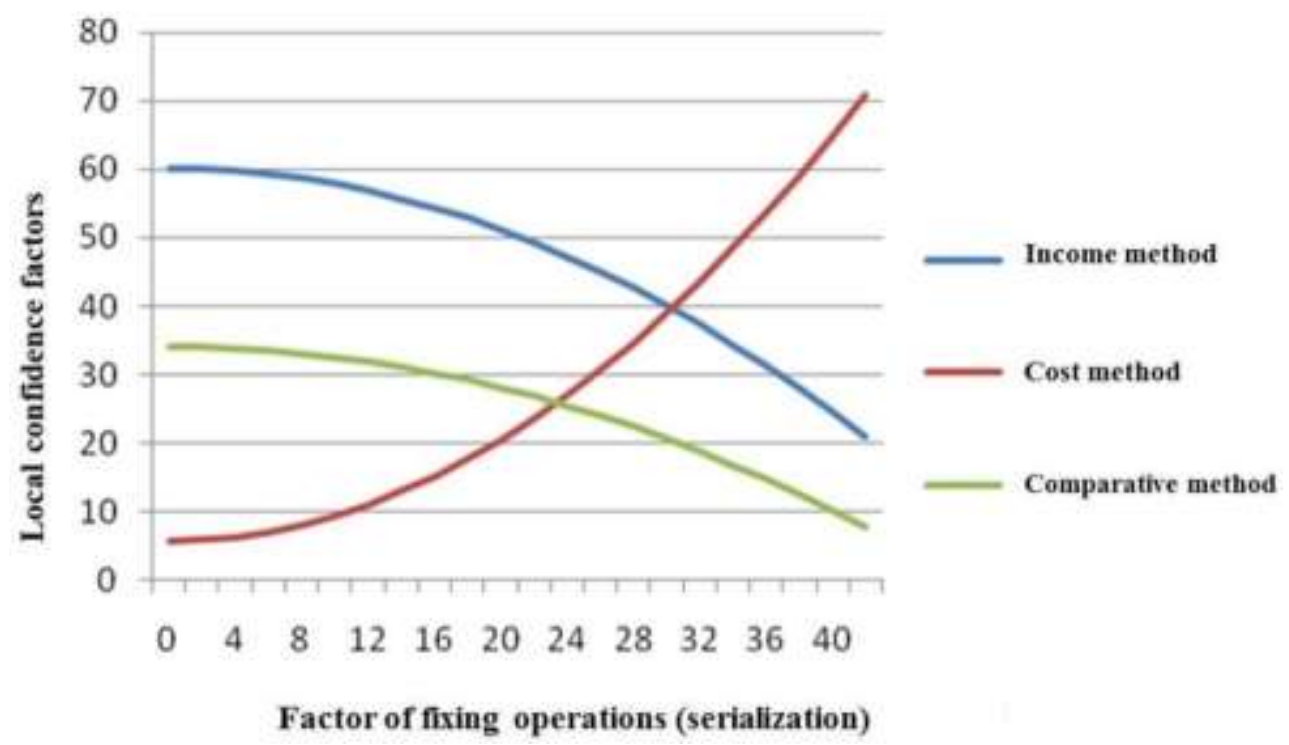

Fig. 2. Graphs of dependencies of local confidence factors on the type of production when using the evaluated IP.

Calculation of the local confidence factors on the basis of the IPlife cycle.

According to the classical ideas about the development of IP, the life cycle of this type of objects consists of the following stages:

1. Development (creation and preparation of IP for implementation).

2. Market promotion (study of demand and refinement of IP).

3. Standardization (use of IP for large-scale purposes).

4. Recession (emergence of new technologies in the direction of the use of IP or related directions).

5. Reanimation (changing IP or developing new ways to use it, taking into account the current level of scientific and technological progress and social trends).

Based on the above 5 stages of the IP life cycle, to characterize the development of IP over time, we will use the "IP Development Stage" indicator, which takes values in the range from 0 to 5 . The "Development Stage" indicator can take any value in the specified range, including fractional, which allows us to more accurately assess the current development of the IP. For example, the "Development" stage may include several consecutive stages of the IP's life, such as the study of analog objects, modeling, testing, refinement, etc.

Thus, the range of values of the "Development Stage" indicator from 0 to 1 corresponds tothe "Development" stage, to the "Market promotion" stage - from 1 to 2, etc. The integer values of the indicator 1, 2, 3, 4 show the borderline state of the object, at which one of the stages of its life cycle has already been completed, and the other has not yet begun.

Using the above-described method of creating neural networks based on expert evaluations followed by approximation of the data and finding the functional dependence, we obtain the following formulas for calculating the local confidence factors on the basis of the IP life cycle:

$$
\begin{aligned}
& \mathrm{LC}_{\mathrm{inc}}=0,59 * \mathrm{~K}_{\mathrm{LC}^{2}}+27 \\
& \mathrm{LC}_{\text {exp }}=65-2,58 * \mathrm{~K}_{\mathrm{LC}}{ }^{2} \\
& \mathrm{LC}_{\text {market }}=2 * \mathrm{~K}_{\mathrm{LC}}{ }^{2}+8
\end{aligned}
$$


$\mathrm{K}_{\mathrm{LC}}$ - "IP Development Stage" indicator

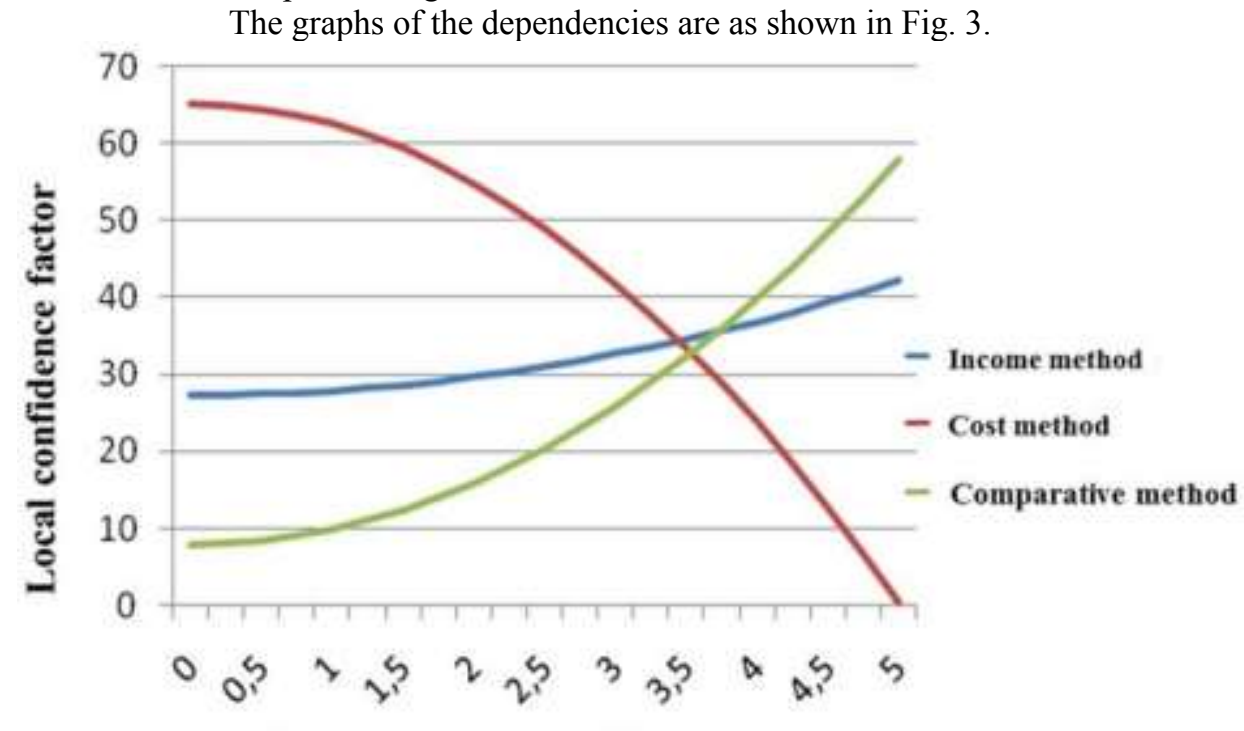

IP development stage (life cycle stage)

Fig. 3. Graphs of dependencies of local confidence factors on the IP life cycle (development stage).

As can be seen from the graph, at the stage of decline in interest in the evaluated IP, the reliability of all evaluation methods is about the same.

Dependence of local significance factor on the type of IP.

The dependence of the local significance factor on the type of IP will be established in accordance with expert evaluations according to Table. 2

Table 2. The significance of the local factor of confidence in the methods of IP evaluation.

\begin{tabular}{|c|c|c|c|c|}
\hline \multirow{2}{*}{ № } & Type of IP & \multicolumn{3}{|c|}{ Local confidence factor } \\
\cline { 3 - 5 } & & $\begin{array}{c}\text { income evaluation } \\
\text { method }\end{array}$ & $\begin{array}{c}\text { cost evaluation } \\
\text { method }\end{array}$ & $\begin{array}{c}\text { comparative } \\
\text { evaluation method }\end{array}$ \\
\hline 1 & Inventions & 40 & 40 & 20 \\
\hline 2 & Utility models & 40 & 40 & 20 \\
\hline 3 & Trademarks & 40 & 20 & 40 \\
\hline 4 & Industrial designs & 40 & 30 & 30 \\
\hline 5 & Computer programs & 50 & 30 & 20 \\
\hline 6 & Database & 40 & 40 & 20 \\
\hline 7 & Chip topology & 40 & 40 & 30 \\
\hline 8 & Selection achievements & 30 & 40 & 10 \\
\hline 9 & Know how & 50 & 40 & \\
\hline
\end{tabular}

Dependence of the local confidence factor from the deviation of the indicator

It is obvious that the results of the evaluation of the same IP cannot significantly differ from each other. It means that the result deviating from the average more than the allowable value was calculated by the method that is least suitable for a particular situation. That is, the factorof confidence in the method of the IPevaluation will be the smaller the greater its deviation from the average value calculated by all methods used in the methodology.

Calculation of the local significance factor on the basis of the purpose of the IPevaluation. 
At its core, the purpose of the evaluation is the expression of the prospect of further use of the object of evaluation. Therefore, it is possible to quantify the purpose of the evaluation through the characteristics of the object acquired in the future. We have proposed to make a quantitative assessment of the quality indicator "Purpose of the IP evaluation" by means of the "Prospects for the use of IP" factor. The "Prospects for the use of IP" indicator characterizes the level of IP dependence (ownership, management) on the current owner (developer) and varies in the range from 0 to 1 . The larger the indicator, the more rights the owner (developer) retains with further IP disposition.

The "Prospects for the use of IP" factor will be defined as the arithmetic average of the values of the indicators "Ownership", "Right of management". The approximate values of the "Prospects for the use of IP" factor for the most common purposes of evaluating IP are given in Table 3

Table 3.The values of the "Prospects for the use of IP" factor for various purposes of evaluation.

\begin{tabular}{|c|c|c|c|c|c|}
\hline № & $\begin{array}{c}\text { Purpose of IP } \\
\text { evaluation }\end{array}$ & Ownership & $\begin{array}{c}\text { Management } \\
\text { right }\end{array}$ & $\begin{array}{c}\text { Prospects for the } \\
\text { use of IP }\end{array}$ & Comments \\
\hline 1 & Sale & 0 & 0 & 0 & Transfer of all rights \\
\hline 2 & Leasing & 0.3 & 0 & 0.15 & $\begin{array}{c}\text { Transfer of management } \\
\text { rights with subsequent } \\
\text { transfer of ownership }\end{array}$ \\
\hline 3 & Franchising & 1 & 0.7 & 0.85 & $\begin{array}{c}\text { Retention of ownership, } \\
\text { partial transfer of } \\
\text { management }\end{array}$ \\
\hline 4 & Pledge & 0.8 & 0.8 & 0.8 & $\begin{array}{c}\text { The risk of losing all } \\
\text { rights to IP }\end{array}$ \\
\hline 5 & Balance & 1 & 1 & 1 & \begin{tabular}{c} 
Retention of all rights \\
\hline
\end{tabular} \\
\hline
\end{tabular}

The study of functional dependencies between the "Prospects for the use of IP"factor and local confidence factors gave the following results:

$$
\begin{gathered}
\mathrm{P}_{\text {inc }}=-21,9 * \mathrm{~K}_{\mathrm{P}}{ }^{2}-18 * K_{\mathrm{P}}+49 \\
\mathrm{P}_{\exp }=19,1 * \mathrm{~K}_{\mathrm{P}}{ }^{2}+15,7 * K_{\mathrm{P}}+18 \\
\mathrm{P}_{\text {market }}=2,8 * \mathrm{~K}_{\mathrm{P}}{ }^{2}+2,3 * K_{\mathrm{P}}+33
\end{gathered}
$$

$\mathrm{K}_{\mathrm{P}}$-"Prospects for the use of IP".

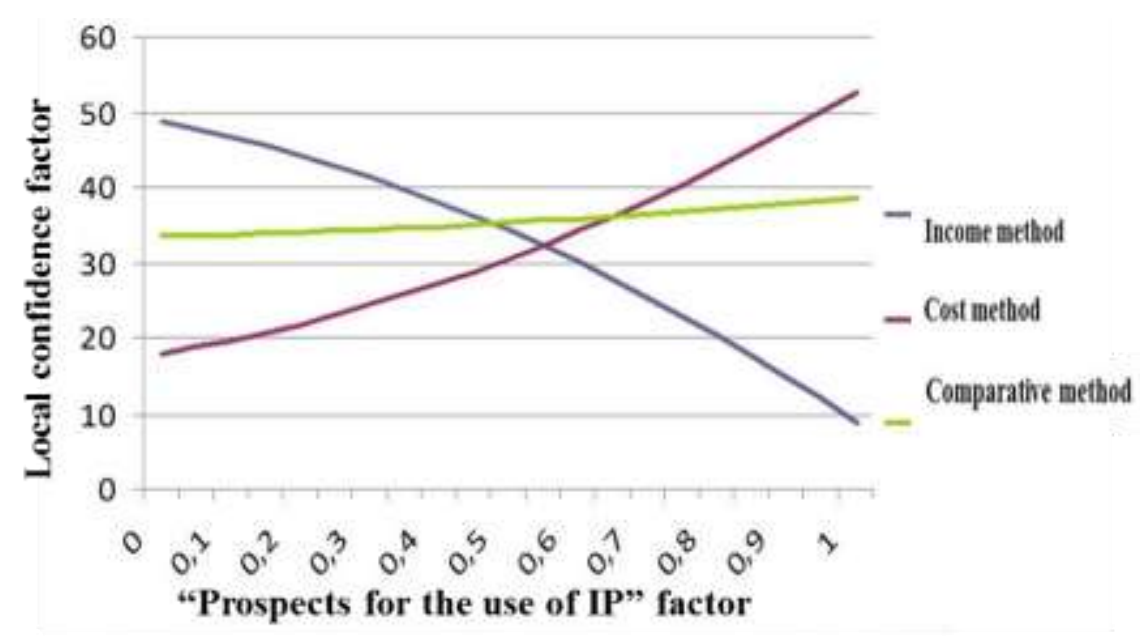

Fig. 4. Graphs of dependencies of local confidence factors on the purpose of the IP evaluation. 
The objective function of the confidence factors of each evaluation method can be represented as follows:

$$
\mathrm{K}=f(\mathrm{~T}, \mathrm{TP}, \mathrm{LC}, \mathrm{P}, \mathrm{D}),
$$

Where T, TP, LC, P, D - local factors of confidenceon the basis of the type of IP, the type of production, the life cycle stage, the purpose of using IP, and the value of the indicator deviation from the average value, respectively.

\section{Discussions}

For intellectual property, in order to increase the objectivity of the calculations, it is possible to use two or more methods of one approach, for example, only income (or cost), since often other approaches cannot be applied for different reasons.

The question of choosing a preferred approach is one of the most difficult, because depending on such a decision, the value of intellectual property can change drastically, and the importance of a correct decision is beyond doubt [9].

Existing methodologies that recommend choosing the preferred approach do not always have accuracy and coverage of all factors of the problem. The choice of approach, of course, depends on the type of object being evaluated, but to a greater extent depends on the purpose of the evaluation, andthe type of value is determinedby the purpose.

The procedures for evaluating intellectual property are complicated by the fact that the true value of these objects is manifested in the future, when they are used and the results of this use are commercialized. And initially it is much more difficult to evaluate objects that have not yet been prepared for placing on the market. Most authors present the classic life cycle as universal, but different IPs have different life cycle models. And even two homogeneous inventions are too dependent on various factors to have the life cycle same bystages, phases, etc.

The authors propose a new method of choosing a defining approach to the economic evaluation of intellectual property depending on goal setting while taking into account the life cycle of an innovative product using neural network modeling. The main achievement of the proposed methodology is to create a model that allows determining the level of confidence in various methods for evaluating intellectual property depending on the values of individual factors of the evaluated object.

Local confidence factors are calculated on the basis of the type of intellectual property, type of production, stage of the life cycle, and purpose of using the object. All previously used methods for evaluating intellectual products have never taken into account these indicators, especially in aggregate. The calculation is made automatically of all the weight coefficients of the income, cost, and comparative method, taking into account the main factors affecting the evaluation of intellectual property. The great advantage of the proposed method is an increase in the accuracy of the calculations used in the evaluation. The use of neural network modeling allows us to quickly take into account hard-to-reach factors and obtain hidden data. This method has a high practical significance, which consists in increasing the accuracy of intellectual property evaluation methods, since all evaluators have to constantly face the choice of the preferred approach.

\section{Conclusion}

The developed method allows us to automatically calculate the weighting coefficients of the income, cost, and comparative method, providing an objective account of the main influencing factors when evaluating the value of IP. 
The main idea of the method is to create a model that allows determination of the level of confidence (the concept of "level of confidence" can be replaced by the concept of "level of significance") for various methods of evaluating intellectual property (IP) depending on the values of individual factors of the object being evaluated.

The method takes into account the totality and interaction of such factors as: type of intellectual property, type of production, life cycle stage, purpose of using the object, deviation of indicators obtained as a result of IP evaluation in various ways. Each of the influencing factors determines the local confidence factor for each method of evaluation separately through the established functional dependence. The aggregate of local confidence factors of one of the evaluation methods forms the resulting confidence factor of this evaluation method, which is its specific weight in the final calculation of the IP value.

\section{References}

1. G.V. Smith, R.L. Parr, Valuation of Intellectual Property and Intangible Assets (John Wiley\& Sons, New York, 1994)

2. E.V. Shpilevskaya, Osnovy ocenki $i$ stoimosti nematerial'nyh aktivov (Feniks, Rostov $\mathrm{n} / \mathrm{D}, 2011)$

3. S.N. D'yakonova, Vestnik ekonomicheskoj integracii 3 (2009)

4. M. Shibayeva, Y. Belykh, Materialy Mezhdunarodnoj nauchno-prakticheskoj konferencii, Kursk, 310-312 (2011)

5. T.V. Nazmeeva, N.I. Vatin, Magazine of Civil Engineering 62(2), 92-101 (2016)

6. R. Rolima, E. Santos, L. Meirac, Region. XI Congreso de Ingenieriadel Transporte, $160-169$ (2014)

7. S.G. Valyuhov, Vestnik MGTU im. N.E. Baumana. Ser. Mashinostroenie 2, 116-127 (2010)

8. S. D'yakonova, N.V. Shigina, Mire nauchnyhotkrytij 6, 193-203 (2012)

9. S.N. D'yakonova, S.A. Kolodyazhnyj, I.S. Surovcev, Ocenkai intellektual'noj sobstvennosti: ucheb. posobie (Voronezh, Voronezhskij GASU, 2014)

10. F. Aggogeri, A. Borboni, R. Faglia, Applied Mechanics and Materials, 373-375, pp. 130-133. (2013) DOI: 10.4028/www.scientific.net/AMM.373-375.130 